\title{
Sobrevivências: considerações sobre arte, gênero e lutas feministas em Pernambuco.
}

\author{
Madalena Zaccara \\ Universidade Federal de Pernambuco
}

\section{Resumo}

Escrita por homens a narrativa histórica da arte se absteve de incorporar às suas preocupações o sujeito feminino. Trata-se de uma História da Arte hegemônica, branca e masculina. No Brasil, a situação não se altera e são raras as publicações que se contrapõem ao discurso da História da Arte oficial, herdeiros que somos da cultura ocidental europeia. No Nordeste do Brasil, a ideia de que a arte para as mulheres é um passatempo, uma prenda a mais para as moças de família abastada, consolidando uma formação voltada principalmente para o casamento, foi bem mais contundente que na região Sudeste aonde as informações (e consequentes mudanças) chegavam mais facilmente. Esse texto traz considerações sobre algumas mulheres artistas que trabalharam (e trabalham) em Pernambuco e das dificuldades por elas enfrentadas.

Palavras Chave: Arte; Gênero; artistas mulheres em Pernambuco.

\section{Abstract}

Written by men, the historical narrative of art abstained from incorporating to its worries the feminine subject. It is a hegemonic, male and white History of Art. In Brazil the situation does not chance and rare are the publications that oposes the official History of Art speech, inheritors that we are of the occidental european culture. In the Northeast of Brazil, the idea is that woman's art is a hobby, another skill to the wealthy family ladies, consolidating a raising more turned to marriage, which is much more strong than in the Southeast region where information (and consequently changes) arrived more easily. This text brings considerations about some of the female artists that worked (and work) in Pernambuco and the difficulties they faced.

Keywords: Art; Gender; female artists of Pernambuco 
As mulheres sejam submissas ao seu próprio marido, como ao Senhor... Como a Igreja está sujeita a Cristo, assim também as mulheres sejam em tudo submissas ao seu marido ${ }^{1}$

Escrita por homens, a narrativa histórica se absteve de incorporar às suas preocupações o sujeito feminino. Este silêncio não foi uma prerrogativa da historiografia brasileira ou latino-americana, mas uma atitude constante inclusive em países hegemônicos onde a preocupação com os direitos femininos e o reconhecimento da sua condição subalterna cronologicamente se processou mais cedo.

Desde a Antiguidade a mulher foi considerada imperfeita por natureza e impotente como as crianças ou os escravos. Excluindo-se as primitivas (e quase desaparecidas) sociedades matriarcais, o papel de liderança e poder sempre coube ao homem. À mulher restava um único poder: o da reprodução. $\mathrm{Na}$ divisão dos papéis dos corpos coube aos homens o heroísmo, o risco, a força, a dureza, a resistência à dor enquanto que a mulher devia se ocupar da graça, do sorriso, da leveza e da fragilidade qualquer que fosse a situação. A maioria das tradições atribui uma importância particular ao papel social da mulher no lar, consagrada às tarefas domésticas, à reprodução e à educação dos filhos. Qualidades e aptidões socialmente diferenciadas deu aos homens o cérebro e às mulheres o sentimento. (PERROT, Michele in BRESCIANI, Maria Stela (org.), 1989) . Essa legitimação da divisão dos sexos para Pierre Bourdieu independe da relação de força:

O sistema mítico-ritual desempenha aqui um papel equivalente ao que incumbe ao campo jurídico nas sociedades diferenciadas (...) ele consagra a ordem estabelecida, trazendo-a a existência conhecida e reconhecida, oficial. (BOURDIEU, Pierre. 2007.p. 17).

Se ao longo da história ocidental sempre houve mulheres que se rebelaram contra sua condição, que lutaram por liberdade, a chamada primeira onda do feminismo, entretanto, aconteceu somente a partir das últimas décadas do século XIX, quando as mulheres organizaram-se para lutar por seus direitos, inclusive o do voto. Para Heloisa Buarque de Holanda, (1994), porém, ainda que o feminismo como ideologia política possa ser identificado desde o século dezenove, é somente a partir dos anos 1970 que ele surge como novidade no campo acadêmico, e se impõe como uma tendência teórica inovadora e de forte potencial crítico e político. Antes das historiadoras foram as feministas que fizeram a história das mulheres.

$\infty<\infty<\infty<\infty<\infty<\infty<\infty<\infty<\infty<\infty<\infty<\infty$

1 Efésios 5:22,24 
As pressões do movimento feminista, desde os anos 70, apoiadas pela entrada maciça das mulheres no mercado de trabalho e na vida acadêmica provocaram uma quebra no silêncio historiográfico e novas produções intelectuais afirmaram a presença da mulher nos mais diversos campos do conhecimento. Essa relativamente recente inclusão tem revelado momentos importantes da presença feminina nos acontecimentos históricos bem como um alargamento do discurso historiográfico, até então estritamente estruturado para pensar as ações individuais e as práticas coletivas como essencialmente masculinas.

Para Mary Del Priore (1989) duas características marcaram o início das produções historiográficas sobre o feminino: fazer emergir a mulher no cenário de uma história pouco preocupada com as diferenças sexuais e demonstrar a exploração, a opressão e a dominação que a vitimava. Os estudos que envolvam questões de gênero em todos os campos do conhecimento desnaturalizam as desigualdades e contribuem para uma efetiva transformação nas relações entre homens e mulheres, equalizando-os. O campo da arte contribui com reflexões que interrogam por que as mulheres foram (e são) excluídas de sua história questionando o papel central que os homens tradicionalmente nela têm ocupado.

\title{
Uma História da Arte hegemônica, branca e masculina.
}

\begin{abstract}
Mais ce qu'il nous fault, c'est la possibilité de travailler comme les hommes et de ne pas avoir a exécuter des tours de force pour en arriver à avoir ce que les hommes ont tout simplement. ${ }^{2}$
\end{abstract}

"Por que não existiram grandes artistas mulheres"? Esse artigo fundamental de Linda Nochlin, (1971), marca o pensamento feminista na História da Arte. Nele, a autora nos mostra o quanto vocações artísticas de mulheres foram apagadas tanto por sua exclusão das instituições quanto pelas regras machistas do mercado de arte.

$\mathrm{Na}$ esteira desta interrogação inicial em relação à exclusão da mulher artista algumas ações aparecem naquele início de década. Em 1971 o "Feminist Art Program" do California Institute of Arts lançou-se como uma iniciativa pioneira nos primeiros estudos feministas em arte. Em 1972, em Nova York aparece o "AIR" (Artists in Residence) tendo como atrativo a presença de Lucy R. Lippard. Naquele mesmo momento, as mulheres artistas criam a Galeria Powerhouse que organiza uma série de exposições

$\infty<\infty<\infty<\infty<\infty<\infty<\infty<\infty<\infty<\infty<\infty<\infty<$

2 ORELL, Pauline apud SAUER, Marina in L'entrée des femmes à l'Ecole des Beaux Arts-1880-1923. Paris, ENSBA. P. 7 
coletivas de artistas mulheres (GRINO, Claire. 2012, p. 5). Nesta linha de pensamento e ação a pesquisa de Rozsika Parker e Grizelda Pollock, publicados em 1981 na Inglaterra, foi também fundamental para uma História da Arte feminista. Intitulada de Old Mistress (1982, pp. 108-110) a publicação faz a crítica do sexismo na História da Arte e demonstra como novas pesquisas podem fornecer as chaves para novos entendimentos sobre o que foi escrito sobre arte no passado. Esse conhecimento permite-nos compreender melhor e mais profundamente a arte de artistas mulheres contemporâneas. É importante recordar que nas obras mais genéricas sobre arte, tanto nas mais "clássicas" quanto nas mais recentes, as artistas mulheres continuam pouco ou nunca mencionadas. Tomando como exemplo os livros de Historia da Arte de Ernest Gombrich ou o popular Janson, em suas primeiras edições, não temos neles qualquer referência às artistas mulheres.

As diferenças fisiológicas entre mulheres e homens têm papel essencial na construção desta história uma vez que é sobre o corpo que se fundamentam as ideias de competência próprias de cada sexo. Como consequência, ele se torna a bandeira da arte feminista juntamente com a sexualidade feminina proibida ou distorcida na maioria das sociedades. É importante ressaltar que mesmo entre criadores e instituições de posições vanguardistas essas diferenças são registradas. Nos espaços pretensamente mais liberais, Claire Grino (2012) cita a análise de Celine Cadaureille sobre três criações de artistas homens que repousam sobre a masturbação masculina comparando as reações a essas ações a outras, paralelas, desenvolvidas por artistas mulheres. Tomando como exemplo Vito Acconci e Linda Benglis, eles têm seu trabalho com o corpo acolhido de forma diversa. Na mesma época em que Acconci se masturba sobre os espectadores uma fotografia de Benglis nua, óculos escuros, e com um vibrador entre as pernas é reprovada pela redação da revista Artforum. Isso nos coloca em face da constatação de que, mesmo no espaço artístico alternativo, anteriormente outsider, os instrumentos de provocação do público não são vistos ou tolerados da mesma maneira em função do sexo do artista.

São, portanto, os trabalhos de pesquisadoras feministas que permitiram descobrir numerosas artistas apagadas pelo tempo e pelo preconceito bem como questionar sobre esta pretensa "sexualidade saudável" que quase sempre é conjugada no masculino. Estas pesquisas feministas mostraram (e mostram) que é necessário desconstruir e renovar os esquemas que estruturam ainda hoje o olhar e consequentemente a História da Arte como disciplina (ou seja, como discurso e ideologia) uma vez que ainda é um olhar branco e masculino (mesmo queer) que predomina como referência na história.

Estudar a arte através do seu discurso canônico hegemônico é reconhecer a masculinidade como um poder capaz de legitimar artistas e obras através de um olhar excludente. Esse olhar, difundido através da academia, é aplicado a um corpus literário ou serve de embasamento para um panteão artístico privilegiando a criatividade masculina. 


\title{
De sinhá prendada a artista plástica: os caminhos da mulher artista em Pernambuco.
}

\begin{abstract}
Depois da experiência do Ateliê Coletivo, que me foi frustrada por imposição paterna, pois eu tinha que conviver também com rapazes, nunca mais participei de outro grupo de arte. Ficou o desenho esporádico quando havia necessidade de um desabafo e só as palavras não conseguiam esvaziar-me. ${ }^{3}$
\end{abstract}

É fora de dúvida que o papel da mulher artista na História da Arte do Ocidente, principalmente até o século XIX e primeira metade do XX, nada mais é que a expressão de sua condição: submissão. O olhar, masculino, ditou as regras, quer fosse o do artista quer o do público. Quando a mulher aparece, em séculos de expressão, ela é o tema e não o ator. Dentro desse universo, elas enfrentavam um espaço dominado pelos homens e para o qual lhes era vedado o acesso. A omissão e a pouca legitimação da mulher artista na História da Arte faz com que novos historiadores passem a questionar esse silêncio histórico que só começa a desaparecer na contemporaneidade. Um silêncio dentro de uma narrativa que é baseada em escolhas e exclusões.

No Brasil, a situação não se altera e são raras as publicações que se contrapõem ao discurso oficial da História da Arte oficial, herdeiros que somos da cultura ocidental europeia. Dessa maneira, no registro histórico brasileiro são pouco conhecidos os nomes de artistas do sexo feminino antes do advento das correntes pós- modernistas. Como nos lembra Ana Mae Barbosa:

\footnotetext{
No Brasil as artistas mulheres do Século XIX e inícios do Século XX foram apagadas da História da Arte. Tiveram sucesso no seu tempo, ganharam medalhas e até prêmios de viagens, mas foram totalmente esquecidas. (BARBOSA Ana Mae. 2010. p. 1979).
}

É importante refletir aqui sobre o espaço de aprendizado artístico destinado às mulheres brasileiras. No que diz respeito ao acesso feminino a uma formação em artes visuais elas só tiveram permissão de frequentar um ensino sistemático, acadêmico, a partir da permissão concedida para a entrada de mulheres na Academia Imperial de Belas Artes, o que só se deu em $1879,{ }^{4}$ o que as deixavam mais frágeis que seus colegas

$\infty<\infty<\infty<\infty<\infty<\infty<\infty<\infty<\infty<\infty<\infty<\infty$

3 RIOS, Nelbe in CLAUDIO, José. Memória do Ateliê Coletivo. Recife: Artespaço. 1975.

4 "No Brasil, a lei que permitiu o ingresso das mulheres nos cursos superiores foi promulgada em 1879, vigorando a partir do último decênio dos tempos imperiais. Até então estava formalmente interditada qual- 
homens em relação ao mercado de trabalho. O próprio processo educacional feminino no Brasil passava, no fim do século XIX e início do XX, pelo conceito estabelecido de uma visão da mulher como um ser desprovido de capacidade intelectual. Dessa forma, a educação se processava de forma diferenciada para os dois sexos: enquanto os meninos eram encaminhados para colégios mais conceituados ou guiados por preceptores, as meninas tinham sua formação voltada para prendas domésticas (entre as quais se destacava a prática da pintura concebida como trabalho manual e parte do dote intelectual necessário às moças de famílias abastadas). Afinal, o projeto de lei sobre instrução pública aprovado em 1827 "deliberava sobre a inclusão e obrigatoriedade, por parte das meninas, de aprendizagem de costura e bordado, sendo que nos Liceus os alunos aprenderiam o desenho necessário às artes e ofícios" ( NASCIMENTO, Erinaldo Alves do., 2010. p. 23)

Além disso, ao longo das tentativas do exercício profissional feminino, a crítica, tão importante no século XIX como veículo de esclarecimento ao novo público consumidor de arte e, posteriormente, como fonte de informações para uma bibliografia referencial, qualificava a presença feminina nos Salões como amadora, situando sua produção como detentora de menor profissionalismo em relação à produção artística masculina. Através de um pequeno trecho da pesquisadora Ana Paula Simioni referindo-se ao historiador Gonzaga Duque fica claro que:

A relação artista $\mathrm{x}$ amador manteve-se como uma categoria relevante para a crítica de arte nacional em textos posteriores. Conforme já foi dito, Gonzaga Duque a reutilizou em seu célebre livro $A$ arte brasileira, publicado em 1888, referência indiscutível para todos os atuais pesquisadores dedicados ao século XIX brasileiro. Na obra, as artistas são acopladas no subcapítulo intitulado "Amadores" que, muito sugestivamente, está localizado após os "Esquecidos" e os "Mortos", um bom indício do espaço marginal que ocupavam na ótica do crítico. (SIMIONI, Ana Paula. 2007)

Dentro desta realidade, apesar da aprovação da lei que permitia seu acesso ao estudo superior elas continuaram sua formação em ateliês particulares de professores vinculados à academia nacional ou fizeram o caminho de alguns de seus colegas masculinos e partiram para Paris em busca da Academie Julien de mais fácil acesso e aberta às artistas mulheres.

quer possibilidade acerca de uma completa profissionalização feminina, excluindo-se o professorado, que não exigia mais do que a Escola Normal. Tal permissão incluía o acesso à Imperial Academia de Belas Artes, mas parece não ter sido imediatamente seguida. Ler SIMIONI, Ana Paula. ENTRE CONVENÇÕES E DISCRETAS OUSADIAS: Georgina de Albuquerque e a pintura histórica feminina no Brasil in Revista Brasileira de Ciências Sociais vol.17 no. 50 São Paulo Oct. 2002. Disponível em http://www.scielo.br/scielo. php?script=sci_arttext\&pid=S0102-69092002000300009 
Muitas mulheres estrangeiras aportavam em Paris procurando a instrução que lhe era vetada em seus países. Entre as brasileiras que se formaram sob a orientação de Rudolph Julian podemos citar a escultora Julieta de França, a pintora Georgina de Albuquerque e a pintora pernambucana Fedora do Rego Monteiro. ${ }^{5}$ As mulheres naquela situação passaram a expor em maior número seus trabalhos nos salões e embora a própria Georgina tenha conseguido, em 1922, ${ }^{6}$ pintar uma tela com tema histórico, território até então reservado aos homens, os assuntos próprios das mulheres - retratos, cenas domésticas e naturezas mortas - continuavam a constituir o imaginário feminino no inicio do século XX. Afinal, essa temática considerada "feminina" era fruto de um processo social de longa duração.

A conquista relativa de uma igualdade entre artistas homens e mulheres no universo artístico brasileiro teve como marco a Semana de Arte Moderna de 1922. Naquele momento os modernistas "comungavam ideias anticolonialistas, que permitiram refletir sobre a igualdade de gênero, raça e códigos culturais" (BARBOSA Ana Mae, 2010.p. 1980). A partir de então algumas mulheres passam a ser reconhecidas como artistas importantes, participativas e o estereotipo de "amadora" parece ter sido posto de lado. É neste momento que vemos surgir no cenário artístico brasileiro as pintoras Anita Malfatti e Tarsila do Amaral as duas grandes artistas brasileiras da primeira metade do século XX.

Tanto Tarsila quanto Anita, entretanto são exceções em uma sociedade de regras masculinas onde as mulheres, dentro de uma ordem silenciosa, são naturalmente "destinadas ao baixo, ao torto, ao pequeno, ao mesquinho, ao fútil etc." (BOURDIEU, Pierre. 2007.p.41). Elas, como tantas mulheres (inclusive as artistas) do passado, suas contemporâneas e sucessoras foram e são submetidas a uma relação de dominação que parte do doméstico e se legitima em instâncias como a escola ou o Estado. Dessa forma, para as poucas mulheres que se destacaram por conta de uma determinada série de circunstâncias, um grande numero delas foi esquecido.

No Nordeste, a ideia de que a arte para as mulheres era um passatempo, uma prenda a mais para as moças de família abastada, consolidando uma formação voltada principalmente para o casamento foi bem mais contundente que na região Sudeste onde as informações (e as consequentes transformações) chegavam mais facilmente. Se naquela região a mulher só participou, com restrições, dos ensinamentos da Academia Imperial de Belas Artes a partir de 1879, em Pernambuco só em 1932 o ensino das Artes Visuais foi sistematizado pela fundação da Escola de Belas Artes. Essa realidade reflete-se na inserção no mercado profissional de trabalho.

$\infty<\infty<\infty<\infty<\infty<\infty<\infty<\infty<\infty<\infty<\infty<\infty$

5 É importante ressaltar a indisponibilidade de um arquivo que contenha maiores informações sobre a frequência feminina na Academie Julien. Já tínhamos esta informação, através da pesquisa de Ana Paula Simioni. Em 2014, em pesquisa realizada por nós nos Arquivos Nacionais de Paris a relação de artistas mulheres que frequentaram aquela academia encontrava-se ainda indisponível.

6 O quadro "Sessão do Conselho de Estado que decidiu a Independência”. 
É importante recordar que, apesar da pintora Fedora do Rego Monteiro ${ }^{7}$, juntamente com Balthazar da Câmara, Henri Moser, Murilo La Greca, Bibiano Silva, Henrique Silva, Henri Moser e Mario Túlio, estar à frente da organização do "II Salão de Arte Oficial de Pernambuco" (em 1930) e do fato de que esse mesmo grupo esteve articulado com a fundação da Escola de Belas Artes de Pernambuco (1932), onde ela, Fedora, ensinará posteriormente, a artista não consta no quadro de sua administração inicial. Os primeiros dirigentes da EBAP foram: Bibiano Silva, diretor; Heitor Maia Filho, vice-diretor; Jaime Oliveira, secretário e Luiz Mateus Ferreira, tesoureiro. O fato nos convida à reflexão, pois, afinal, inegavelmente, Fedora do Rego Monteiro era a presença que mais se destacava no contexto profissional das Artes Visuais em Pernambuco na década de 30 , com um currículo bem mais sólido e cosmopolita em relação aos seus companheiros da EBAP.

A partir de $1942{ }^{8}$ através de um decreto estadual, instituiu-se o "Salão Anual de Pintura no Museu do Estado de Pernambuco", "onde foram expostos apenas trabalhos de pintura à óleo e predominou a participação de alunos e professores da Escola de Belas Artes do Recife" (BARBOSA, Kleumanery de Melo, 2002.p 6). .Os Salões constituíam, então, o principal evento artístico realizado no Estado: um símbolo do desenvolvimento das Artes Visuais em Pernambuco e vitrine para o reconhecimento e validação da produção artística. Segundo a imprensa local:

Em Pernambuco há um ambiente artístico, que nesses últimos tempos, alcançou desenvolvimento bem digno de nota; e no que diz respeito à pintura talvez mesmo mais do que a outras manifestações da $\operatorname{arte}(\ldots)^{9}$

Nesse cenário, a artista Fedora do Rego Monteiro, (fig. 1) uma das fundadoras da Escola de Belas Artes de Pernambuco, membro do seu corpo docente e personalidade atuante no universo das artes plásticas - tendo participado, por exemplo, do Salon des Independentes de 1913, em Paris, realizado individual no Rio de Janeiro em 1915 e organizado o II Salão de Arte Oficial de Pernambuco - parece ser exceção. Analisando as premiações dos Salóes acontecidos ente 1942 até 1947, quando a própria Fedora ganha um segundo prêmio, só aparece o seu nome como expressão do universo feminino nas

$<<<<<<<<<<<<<<<<<<<<<<<<<$

7 Fedora do Rego Monteiro Fernandes (Recife, 3 de fevereiro de 1889 --- Recife, 1975) foi uma pintora, desenhista e professora brasileira nascida em Pernambuco.

8 Decreto Estadual 725 de 25 de abril de 1942 apud Kleumanery de Melo Barbosa, Dos Salões de Arte em Pernambuco. Monografia para conclusão do curso de Graduação em Licenciatura em Desenho e Plástica sob a orientação da Prof. Marilene Melo de Almeida. Universidade Federal de Pernambuco. 2002.

9 Nota em jornal da época, não identificado, pertencente à Memória do Museu do Estado. Ler Kleumanery de Melo Barbosa em Dos Salões de Arte em Pernambuco, Op Cit, 2002. p. 18. 
artes visuais de Pernambuco. No que diz respeito à comissão julgadora do Salão, só em 1950 vemos a presença de uma mulher: Lygia E. de Oliveira.

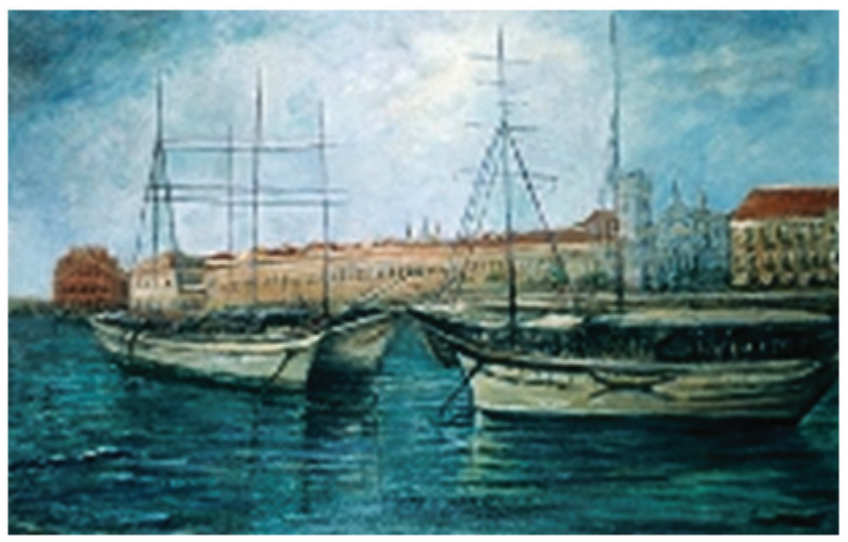

Figura 1

Fedora do Rego Monteiro. Porto Pesqueiro do Recife

óleo s/ chapa de madeira industrializada (década de 1950), ass. inf. dir.

$75 \times 118 \mathrm{~cm}$

É importante lembrar que, quase paralelamente à implantação da Escola de Belas Artes, um grupo de jovens artistas rompia com seus ensinamentos e criava o "Grupo dos Independentes" que praticava valores estéticos inovadores e trazia o vocabulário moderno para o cenário pernambucano. Desenhistas, caricaturistas, pintores e escultores compunham o grupo e fundaram os primeiros "Salões Independentes de Arte" entre 1933 e 1936. Independência de tudo que fosse tradicional era a regra. O "Grupo dos Independentes" também não tinha, entre seus fundadores, nenhuma mulher. Entretanto, na mostra realizada no "I Salão dos Independentes" observarmos as presenças de Fedora Monteiro e Crisolice Lima - em um universo de 22 artistas homens - o que demonstra que elas eram artistas competentes e atuantes. (RODRIGUES, Nise de Souza, 2008)

Apesar da atuação do "Grupo dos Independentes", a consolidação do modernismo em Pernambuco, só ocorreu a partir da formação da Sociedade de Arte Moderna de Recife em 1948. Conduzida pelo escultor Abelardo da Hora e pelo pintor Hélio Feijó ela congregou a vanguarda das artes plásticas e dos intelectuais de Recife. Entre seus membros temos a presença de quatro mulheres: Ladjane Bandeira, Tereza Costa Rego, Tilde Canti e Maria de Jesus Costa o que, de certa forma, representava um avanço da presença da mulher artista no contexto pernambucano.

O período posterior à queda do Estado Novo (e a incorporação gradativa do vocabulário modernista, trazendo um universo mais libertário para o país e, consequentemente, para Pernambuco), talvez tenha se refletido no aumento do número de mulheres participantes das atividades artísticas na capital do Estado. No "Salão Anual de Pintura", de 1950, que apesar do nome deu espaço para a presença da escultura, por exemplo, vemos um percentual bastante significativo de mulheres premiadas em relação aos homens. Para 14 prêmios quatro foram concedidos a mulheres: Fedora do Rego Monteiro, 
que arrebatou o segundo prêmio, Clélia Reis, Daura Melo e Tilde Canto. Finalmente, o Salão de 1951 concede o primeiro prêmio a uma mulher: a artista e jornalista especializada em crítica de arte Ladjane Bandeira. (BARBOSA, Kleumanery, 2002).

Ser artista profissional, porém, ainda não era atividade fácil no Brasil e muito menos em Pernambuco. A empreitada, para a mulher, significava encarar sua produção como um simples passatempo ou viver uma opção de certo risco: quase uma rebelião. A situação abrangia todas: sem distinção de credo político ou classe social. Para Tereza Costa Rego (fig. 2), artista pernambucana ligada aos movimentos de esquerda e atuante no modernismo pernambucano, segundo a jornalista Joana Rozowykwiat, a iniciação nas artes visuais aconteceu no seguinte contexto:

Filha de uma família tradicional da aristocracia rural teve educação rígida e repressora. (...) aprendeu a ser forte e independente. Rebelou-se contra o estigma de "bonequinha que enfeita o piano na sala de visitas" e, hoje, coloca pra fora, por meio de sua arte, tudo que guardava calada. (ROZOWYKWIAT, Joana,2003)

De acordo com Adriano Carvalho, referindo-se ao trabalho atual da artista pernambucana nascida em 1929:

Uma das maiores contribuições de Tereza Costa Rego à historia da arte pernambucana é justamente a profunda reflexão sobre a identidade feminina que se apresenta na poética de muitos dos seus quadros e gravuras. É a resposta proferida por uma mulher moderna à realidade social caduca e opressora que insiste em colocar distinções hierárquicas sobre os gêneros ainda nos tempos hodiernos. (CARVALHO, Adriano. 2014.p.17.)

Nitidamente vemos que a arte era encarada no início do século XX, em Pernambuco, como uma atividade de moça prendada e era necessário um processo de rebelião para a concretização dos anseios de uma mulher artista que se via tolhida pela sociedade que a cercava. Pouco a pouco, entretanto, ela passou a escolher caminhos: abandonou uma arte considerada "feminina", amadorística e passou a integrar um mercado de trabalho, distante da "bonequinha que enfeita o piano na sala de visitas", ou continuava a pintar aquarelas para orgulho familiar como parte do dote proporcionado para uma posição bem sucedida no mercado de casamentos, que não foi o destino específico de Tereza Costa Rego, mas que engoliu tantas mulheres de sua época. Para Maria Carmem, artista pernambucana radicada em Olinda, a primeira opção foi o caminho escolhido com todos os percalços inerente a este caminho. Diz ela: "Nasci artista, mas era solicita- 
da a consertar os objetos quebrados da família, chamavam-me de prendada, e a isso eu tinha horror". ${ }^{10}$

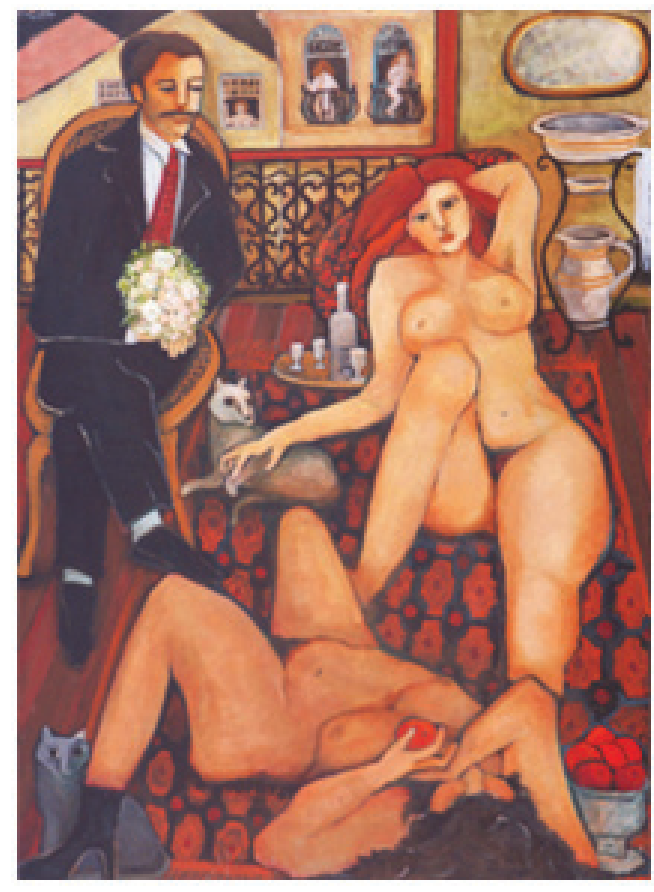

Figura

Tereza Costa Rego. Bairro do Recife.

Acrílico sobre madeira.

$1,60 \times 2,20 \mathrm{~m} 1992$.

Essa foi a opção de Maria Carmem: evitar o ser "prendada” como alternativa ou destino final para as mulheres criadoras de sua geração. Mas, como a modernidade oficializada em Pernambuco viu a presença da mulher na produção das artes visuais? $\mathrm{O}$ "Ateliê Coletivo" da "Sociedade de Arte Moderna do Recife" era um mundo só de homens? Guita Charifker diz que não totalmente: "tinha Celina Lima Verde, Maria Jesus Costa e eu. Mas ainda éramos minoria. Representava um milagre naqueles idos de 54, podermos frequentar um atelier onde predominavam homens"11

De fato, a proporção era desigual. No "Salão Anual de Pintura de 1954", foram premiadas três artistas mulheres em um universo de trinta expositores contemplados. Além da própria Guita, que recebeu o "Prêmio Universidade de Recife" e Maria de Jesus Costa e Ivone Azevedo que receberam "Menção Honrosa" no Salão. Entretanto, a Sociedade de Arte Moderna do Recife, desde sua fundação, aparentemente deu certo espaço para as mulheres mesmo em um universo de membros predominantemente masculino.

$\infty<\infty<\infty<\infty<\infty<\infty<\infty<\infty<\infty<\infty<\infty<\infty$

10 Depoimento concedido à Clarissa Diniz in Crachá. Aspectos da legitimação artística. Recife: Governo de Pernambuco. FUNCULTURA, 2008.p.17.

11 Depoimento concedido à José Cláudio in Memórias do Ateliê Coletivo, Recife, p.43 
O seu ex-tesoureiro, o artista Wilton de Souza (1975) comenta, em depoimento no livro "Memória do Ateliê Coletivo" de José Cláudio, que a pintora Ladjane Bandeira chegou a ser presidente da SAMR antes da criação do Ateliê Coletivo. A conquista do posto não deve ter sido fácil, principalmente se levarmos em conta que entre os 46 membros da sociedade somente oito eram do sexo feminino e só quatro, artistas plásticas. Mas, devemos levar em conta a atuação pioneira de Ladjane que foi a primeira crítica de arte de Pernambuco e atuava nos principais órgãos de comunicação da cidade.

Maria de Jesus Costa, na época estudante de arquitetura, em depoimento para o mesmo livro nos diz que "inicialmente eu era a única mulher a frequentar com assiduidade o ateliê" e que "ser de fato artista plástico, viver só de arte (...) não era possível". Sobre as dificuldades encontradas então, outra artista que frequentou o Ateliê Coletivo, Nelbe Rios (1975), naquele mesmo livro, também se pronuncia, analisando as excursões dos seus membros para o exercício de desenho rápido .Diz ela que essas excursões não eram vistas com bons olhos por seu pai, de ideias tradicionalistas quanto à educação de uma moça, como também não era admitida a possibilidade de arte vir a ser um meio de vida principalmente para uma mulher. Através desses depoimentos nos resta uma unanimidade: apesar da constatação da presença da mulher nesse momento das Artes Plásticas em Pernambuco, os tempos eram ásperos e as dificuldades por vezes intransponíveis. Se para o artista homem eles eram difíceis, para a mulher representavam um desafio bem maior.

O golpe militar de 1964 transformou o Nordeste do país em zona perigosa. Uma verdadeira "diáspora cultural", nas palavras de Ana Mae Barbosa (1997), aconteceu espalhando artistas e intelectuais entre o Rio de Janeiro e São Paulo. O Movimento de Cultura Popular, criado em maio de 1960, que teve uma atuação marcante oferecendo uma formação artística gratuita, deixou de existir. As atividades culturais que aconteciam na Faculdade de Direito tiveram fim e, mesmo a natureza, pareceu não colaborar com as Artes Visuais com a destruição da Galeria do Recife por uma cheia do Rio Capibaribe.

A agitação cultural que aconteceu em Recife, antes da repressão, teve à frente algumas mulheres que compunham a cena na época: Guita Charifker, por exemplo, parece ter estado presente em todos os acontecimentos que envolveram esses tempos. Ensinou no "Ateliê Coletivo do Movimento de Cultura Popular", expôs na "Galeria do Recife", participou da mostra "Civilização Nordeste", organizada por Lina Bo Bardi em Salvador e foi co - fundadora do "Movimento da Ribeira", em Olinda, que a teve como um de seus organizadores e professores. Foi também em Olinda que ela montou ateliê onde trabalha até os dias que correm. São dessa veterana as palavras que, em entrevista a Ronaldo Correia Brito, definem a situação, naquele momento, dessas artistas pioneiras:

Atualmente, quase todas as mulheres pintam. Naquela época poucas eram as mulheres que pintavam e tinham a coragem de assumir as posturas que assumi. Ao me entregarem o Troféu Cultural Cidade 
do Recife - 2000 é como se tivessem premiado as fantasias de uma menina que um dia sonhou ser artista e conseguiu. ${ }^{12}$

Tempos difíceis de fato, mas foram essas artistas que atuaram nos tempos do "Ateliê Coletivo" que vão influenciar a geração dos anos 80 quando se inicia no Brasil a abertura política rumo à redemocratização do país. A antiga geração se junta à nova e se engaja politicamente através das "Brigadas de Arte". Vamos encontrar, por exemplo, Tereza Costa Rego e Bete Gouveia na "Brigada Portinari"13 . Duas gerações de mulheres artistas interferindo nos muros e na paisagem urbana de Recife e em seu próprio destino enquanto artistas.

Porém, mesmo na segunda metade do século XX, a arte como profissão para a mulher ainda não era bem vista. Bete Gouveia, (fig. 3) artista plástica e professora da Universidade Federal de Pernambuco, em entrevista à autora ela afirma que sua família, muito conservadora, nunca apoiou sua opção pela arte. Queria que fosse dona-de-casa ou, no caso de ter uma formação acadêmica, que seguisse Arquitetura ou Direito. A tradição familiar brasileira, patriarcal e conservadora, com essas características bem mais fortes no contexto nordestino, queria um saber mais convencional para seus filhos e principalmente para suas filhas. Para algumas famílias, artistas em geral mantinham o mesmo status social próprio do século XIX quando a profissão de artista era uma alternativa própria das classes menos privilegiadas. Para a mulher, naturalmente, as ressalvas eram bem maiores.

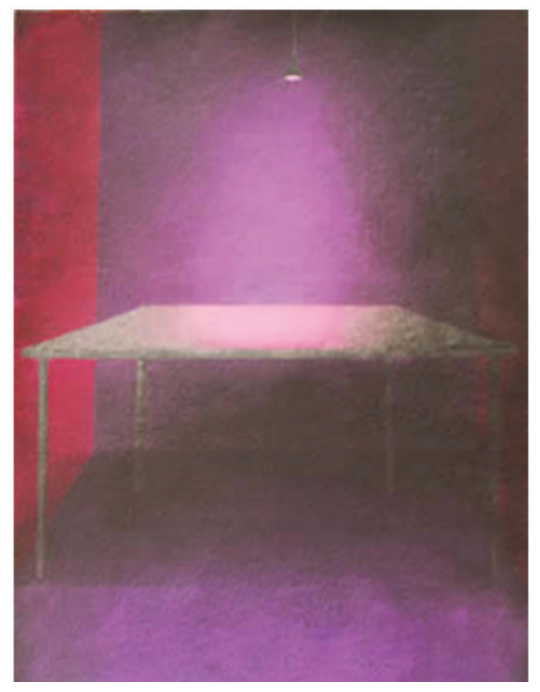

Figura 3

Bete Gouveia. Clarescuro. 2009.

$\infty<\infty<\infty<\infty<\infty<\infty<\infty<\infty<\infty<\infty<\infty<$

12 Depoimento a Ronaldo Correia de Brito disponível em http://www.continentemulticultural.com.br/index.php?option $=$ com_content\&view $=$ article\&id $=153$

13 A Brigada Portinari foi criada no inicio dos anos 80 por artistas pernambucanos. Tinha inspiração político/partidário. 
Durante os anos 80, os Salões passaram a ser reconhecidos como um importante fator para o desenvolvimento e validação da produção artística no Estado. O antigo "Salão Anual de Pintura" foi rebatizado de "Salão de Artes Plásticas de Pernambuco" e abriu-se para novas categorias. Observando sua premiação, vemos que o número de mulheres artistas, embora inferior se comparada com os homens, cresce e se estabiliza. Entre as mulheres artistas e premiadas atuantes no cenário pernambucano temos Liliane Dardot que recebe o prêmio "Grandes Moinhos do Brasil” em 1983, Bete Gouveia, que tira o primeiro prêmio em 1986, Alice Vinagre, premiada em segundo lugar no mesmo salão e Jeanine Toledo com "Menção Honrosa” no Salão de 1989.

A década de 90 traz mudanças no âmbito internacional que se refletem no cenário nacional e regional com a rapidez com que os meios de comunicação globalizaram o planeta. Transformações políticas e sociais aliadas a conquistas científicas redimensionaram o comportamento e o olhar. As artes visuais refletem esse novo panorama e o Nordeste, apesar de seu deslocamento do eixo de poder Rio - São Paulo acompanha essas mutações. Pernambuco está na linha de frente desses novos tempos na região e a instalação de aparelhos culturais atuantes em sua capital e a atividade dos grupos de artistas, pensando e trabalhando em conjunto, provocaram um novo olhar local que vai se fortalecer gradativamente. A presença da mulher nesse novo contexto se faz notar desde sua posição enquanto gestora dessas novas instituições culturais, como é o caso do Instituto de Arte Contemporânea (IAC) que teve em seu período de existência nove gestores, a administração de seis mulheres: Helena Pedra, Maria do Carmo Nino, Oriana Duarte, Ana Lisboa, Bete Gouveia e Renata Wilner. O IAC foi fundamental para a formação de um novo olhar em Pernambuco através de ações experimentais e da função pedagógica de suas palestras e Workshops.

Através da ação isolada, em grupo, ou inserida no contexto dos Salões e das instituições culturais, a mulher artista em Pernambuco se fortaleceu sensivelmente a partir dessa década. No que diz respeito aos grupos de artistas temos o exemplo de Oriana Duarte que fez parte do "Grupo Camelo" onde as relações entre seus componentes aconteciam, de acordo com relato de um de seus membros, a partir de uma parceria onde a cumplicidade, confiança e a interação demarcavam o desempenho. Dessa trajetória comum, Marcelo Coutinho, um dos componentes do "Camelo", em entrevista concedida à crítica de arte Clarissa Diniz publicada em seu livro Crachá (2008) diz:

(...) No início éramos eu, Ismael Portela, Jobalo, Paulo Meira e Oriana (Duarte). Toda semana nos encontrávamos e bebíamos até cair. (...) Éramos os xiitas do Camelo, pelo fato de que nós estávamos presentes o tempo inteiro, decidíamos tudo junto, levávamos tudo às últimas consequências, consumíamos todo nosso dinheiro e tempo com o grupo. ${ }^{14}$

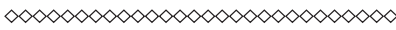

14 Depoimento concedido à Clarissa Diniz in Crachá. Op. Cit. 2008. 
Contextualiza-se, na época, uma relação de igualdade no que diz respeito ao comportamento e à ideologia do grupo. Dentro desse mesmo espaço de associações entre artistas onde uma mulher participa sem noções hierárquicas e que envolve uma troca de conhecimentos está a experiência que teve lugar no ateliê de Christina Machado quando ela, detentora de um saber cerâmico, passou a dividi-lo com artistas plásticos já inseridos no meio das artes visuais em Pernambuco. Através dela, Joelson juntamente com Zé Paulo e Rinaldo desenvolveram sua curiosidade sobre o barro no espaço da casa / ateliê de Christina que lhes ensinou a lidar com o material. O grupo de artistas continuou a trabalhar junto, incorporando, posteriormente, Dantas Suassuna e bebendo nas fontes dos artesãos oleiros pernambucanos em projeto que derivou na exposição internacional "Gambiarra" realizada na França.

No panorama da década não podemos esquecer o programa Rumos Visuais Itaú que, mapeando o cenário nacional da arte, teve em sua primeira versão oito artistas pernambucanos, ou atuantes no Estado, selecionados . Entre os oito artistas, três mulheres se fizeram presentes: Oriana Duarte, (fig. 4) Giovanna Pessoa e Renata Pinheiro. Era o início de uma possível relação de paridade para a mulher artista em Pernambuco. (ROSENBERG, André; TEJO, Cristiana. 2002).

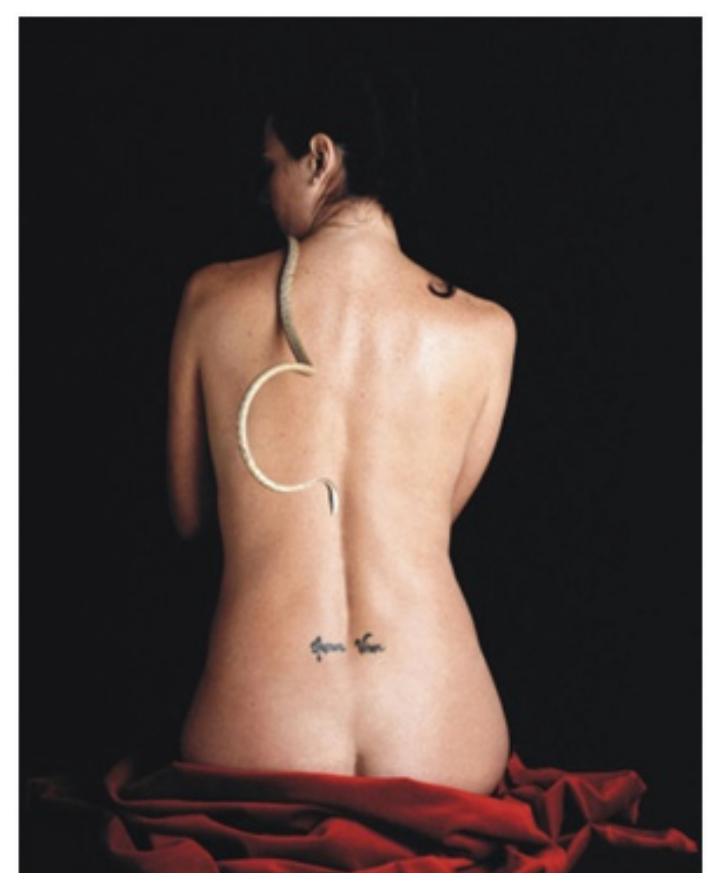

Figura 4

Oriana Duarte. Selvagem Sabedoria, 2004,

fotografia em metacrilato.

A escolha da obra de Oriana Duarte "Selvagem Sabedoria", aqui, nesse contexto de uma contribuição para a história da mulher em Pernambuco não foi casual. Discutir o feminino em qualquer dos seus aspectos, inclusive o do seu apagamento histórico, en- 
volve um mergulho na alma feminina renegada e subjugada durante séculos de dominação patriarcal. O registro do feminino foi e é marcado por mecanismos repressivos que margeiam a sua essência e interrompem a sua livre expressão. O imaginário feminino existe, em sua maior parte, em função do poder masculino.

A diferença biológica entre os sexos, entre o corpo masculino e o feminino, aparece ao longo da história como uma justificativa socialmente construída para a subordinação do feminino e a determinação do espaço da mulher nas diversas sociedades através da "naturalização" dessa construção androcêntrica que determina o papel da mulher em todos os campos, inclusive o do criar. Apesar de todas as conquistas feministas que acreditamos terem rompido com as formas tradicionais de controle do seu corpo, ele continua manipulado, exibido e subordinado ao olhar masculino. Para isso basta ligarmos a televisão, abrirmos uma revista e verificarmos o quanto o corpo da mulher é ainda oferecido e disponibilizado simbolicamente em quase todas as formas de publicidade dos mais variados objetos de consumo.

Oriana Duarte apresenta, nessa imagem que é um palimpsesto (fazendo referências sucessivas a "Grande Odalisca” de Ingres e a fotografia "Le Violon d'Ingres" de Man Ray que teve como modelo Kiki de Montparnasse), seu próprio corpo para além das armadilhas do poder exercido sobre ele. $\mathrm{O}$ seu, é um corpo não domesticado que pode se fazer poética criadora a partir da transgressão. Seu corpo como instrumento e que, sob seu controle, se constitui em seu autorretrato. Esse corpo fronteira, descolonizado é simbólico em relação às lutas feministas em Pernambuco: um signo de libertação. $\mathrm{O}$ termo selvagem desperta inquietações evocando aspectos instintivos extremamente negados por nossa cultura ocidental. O selvagem apresenta uma integridade inata e limites saudáveis de sua identidade, distanciando-o do seu atual sentido pejorativo que simboliza algo fora de controle. $\mathrm{O}$ instinto nos remete a mulher que uiva, ama, chora, guerreia, e que transforma essa luta em arte.

\section{Referências bibliográficas}

BARBOSA Ana Mae. Uma questão de política cultural: mulheres artistas, artesãs, designers e arte-educadoras. In Anais do $19^{\circ}$ Encontro da Associação Nacional de Pesquisadores em Artes Plásticas, 2010 Disponível em http://www.anpap.org.br/anais/2010/ pdf/ceav/anna_mae_tavares_bastos_barbosa.pdf

Artes Plásticas no Nordeste. In: Estudos Avançados. Vol. 11.

São Paulo, 1997.

BARBOSA Kleumanery de Melo. Dos Salões de Arte em Pernambuco. Monografia para conclusão do curso de Graduação em Licenciatura em Desenho e Plástica sob a orientação da Prof. Marilene Melo de Almeida. Universidade Federal de Pernambuco. 2002. 
BATISTA, Marta Rosseti. Os artistas brasileiros na Escola de Paris: anos 1920. São Paulo: Editora 34, 2012.

BONNET, Marie Jo. Les femmes dans l'art. Qu'est-ce que les femmes ont apporté à l'art ? Paris: Éditions de la Martinière, 2004.

BOURDIEU, Pierre. A Dominação Masculina. Rio de Janeiro: Editora Bertrand. 2007.p. 17.

CARVALHO, Adriano. Tereza Costa Rego na Oficina Guaianases de gravura: uma contribuição para o resgate da memória artística em Pernambuco in ZACCARA, Madalena, SILVA, Maria Betânia (org.) Cruzamentos Estéticos em Artes Visuais. Recife: UFPE, 2014.

CLAUDIO, José. Memória do Ateliê Coletivo. Recife: Artespaço.1975.

DINIZ, Clarissa. Crachá. Aspectos da legitimação artística. Recife: Governo de Pernambuco. FUNCULTURA, 2008.

HOLLANDA, Heloisa, B. Feminismo em tempos pós-modernos. In HOLANDA, Heloisa (Org.). Tendências e impasses: o feminismo como crítica da cultura. Rio de Janeiro: Rocco, 1994.

DEL PRIORE, Mary. A Mulher na História do Brasil. São Paulo: Contexto, 1989.

GRINO, Claire. Sexes à bras-le-corps In Inter Art Actuel n. 112. Quebec: Les Éditions Intervention,2012,

LAPONTE, Luciana Gruppelli. Sexualidade, Artes Visuais e Poder. Pedagogias visuais do feminino in Revista Estudos Feministas, vol10, numero 2.Rio de Janeiro:UFRJ,2002

NASCIMENTO, Erinaldo Alves do. Ensino do desenho: do artífice/artista ao desenhista auto- expressivo. João Pessoa: Editora UFPB, 2010

NOCHLIN, Linda. Why Have There Been No Great Women Artists? In http://deyoung.famsf.org/files/whynogreatwomenartists_4.pdf

PERROT, Michele. Práticas da Memória Feminina in BRESCIANI, Maria Stela (org.). Revista Brasileira de História - no. 18 - SP - ANPUH/Marco Zero -1989/90.

SAUER, Marina. L'entrée des femmes à l'Ecole des Beaux Arts-1880-1923. Paris, ENSBA.

PARKER, Rozsika; POLLOCK, Griselda. Old Mistresses: Women, Art and Ideology. In: Feminist Review N. 12, 1982, pp. 108-110.

RODRIGUES, Nise de Souza, O grupo dos independentes: arte moderna no Recife-1930. Recife; Editora da Aurora, 2008.

ROSENBERG, André, TEJO, Cristiana. Artes Plásticas in Pernambuco: cinco décadas de arte. Recife: Gráfica Santa Marta, 2002 
ROZOWYKWIAT, Joana. Tereza Costa Rego Quadro a Quadro, 2003 disponível em http://portalolinda2.interjornal.com.br/noticia.kmf?noticia $=1194171 \&$ sessao $=150 \&$ tot $\mathrm{al}=12 \&$ indice $=0$

SIMIONI, Ana Paula Cavalcanti. Profissão Artista: Pintoras e Escultoras Acadêmicas Brasileiras São Paulo: Edusp, 2008.

Entre convenções e discretas ousadias: Georgina de Albuquerque e a pintura histórica feminina no Brasil. In: Revista Brasileira de Ciências Sociais vol.17 no.50 São Paulo Oct. 2002. Disponível em http://www.scielo.br/scielo. php?script=sci_arttext\&pid=S0102-69092002000300009

. As mulheres artistas e os silêncios da história: a

história da arte e suas exclusões. In labrys, études féministes/ estudos feministas janvier /juin 2007 - janeiro / junho 2007 disponível em http://www.labrys.net.br/labrys11/ecrivaines/anapaula.htm. Acesso em 10 de outubro de 2015.

ZACCARA, Madalena. Anotações sobre a presença da mulher nas Artes Visuais em Pernambuco. In: ZACCARA Madalena, PEDROSA, Sebastião. Artes Visuais e suas Conexões: panorama de Pesquisa. Recife: Editora da UFPE, 2010.

Uma artista mulher em Pernambuco no início do século XX:

Fédora do Rego Monteiro Fernandez in 19\&20, Rio de Janeiro, v. VI, n. 1, jan./mar. 2011. Disponível em: http://www.dezenovevinte.net/artistas/frm_mz.htm 